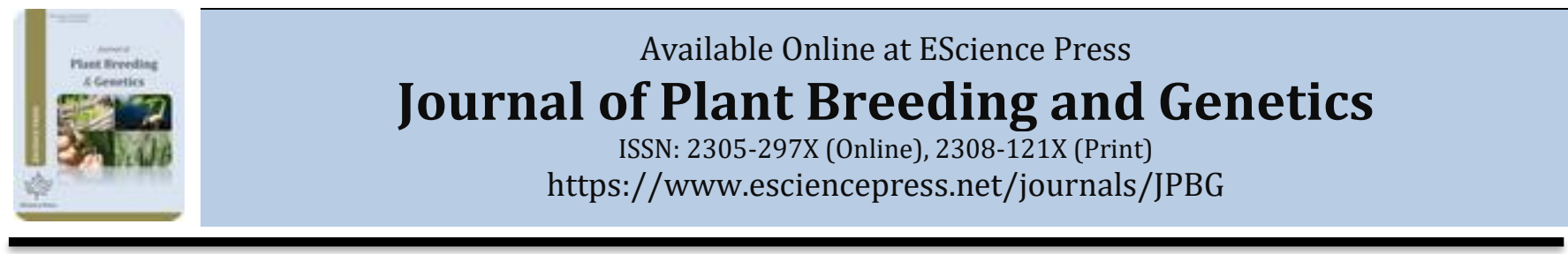

\title{
A DIHAPLOID APPROACH FOR THE SELECTION OF FORAGE QUALITY IN TALL FESCUE (FESTUCA ARUNDINACEA SCHREB.)
}

aBryan Kindiger, bJoseph Moyer

aUSDA-ARS, Grazinglands Research Laboratory, El Reno, OK, United States.

b Kansas State University, Southeast Kansas Research Center, 25092 Ness Rd., P.O. Box 31, Parsons, KS 67357, United States.

Corresponding Author Email: Email: bryan.kindiger@ars.usda.gov, Tel \& fax: 1-405-262-5291, 1-405-262-0133.

\begin{abstract}
A B S T R A C T
Within the Festuca-Lolium genome complex, there is a need for modern breeding approaches that can facilitate the rapid development of improved germplasm or cultivars. Traditional recurrent or mass-selection methods for population or synthetic development are labor intensive and time consuming. The recent development of annual ryegrass Lolium multiflorum Lam.) lines, when hybridized by tall fescue [(Festuca arundinacea Schreb. (syn. = Lolium arundinaceum (Schreb.) Darbysh.)], will produce F1 hybrids, that through mitotic genome loss, lose either their ryegrass or tall fescue genome and result in the recovery of ryegrass and tall fescue dihaploid (DH) lines. For breeding and selection purposes regarding forage quality, the ability to select for superior genotypes at the F1 generation, rather than at the subsequent DH generation would improve the efficiency of the technique. The study examined forage quality components of crude protein (CP), acid digestible fiber (ADF), neutral digestible fiber (NDF) and in vitro dry matter digestibility (IVDMD) expression and inheritance in the F1 and their respective recovered DH lines. Results of the study indicate that forage quality genotypes, conferred by the tall fescue gamete, are heritable and selection performed at the F1 generation will be effective in identifying DH genotypes that are not significantly different in forage quality of their respective F1 parents. Though performed only on CP, ADF, NDF and IVDMD forage quality components, the study suggests similar application toward the selection of additional quantitative forage quality or agronomic attributes for tall fescue improvement. The described selection strategy is applicable to tall fescue (L. arundinaceum) and may have application across the Lolium/Festuca genus.
\end{abstract}

Keywords: dihaploid, tall fescue, forage, quality.

\section{INTRODUCTION}

Tall fescue (Festuca arundinacea Schreb. (syn. = Lolium arundinaceum (Schreb.) Darbysh.; Schedonorus arundinaceus (Schreb. Dumort.)), 2n=6x=42, represents the predominant, introduced perennial cool-season grass forage in the USA. Its wide adaptation, spring, summer, and fall forage production, deep root system, tolerance to heat and persistence make this a desirable species for hay, pasture and turf. It responds well to fertilizer but can maintain itself under limited fertility and is adapted to moderately acid and wet soils (Jennings et al., 2008). Tall fescue is a self-incompatible, outbreeding allohexaploid that represents a species complex consisting of Continental, Mediterranean and rhizomatous (Hand et al., 2010). Its diversity of genotypes varies in morphology, agronomic attributes, persistence, drought and other agronomic attributes which have and are the focus of various breeding or selection schemes (Kasperbauer, 1990; Humphreys et al., 1997; Volaire and Norton, 2006). However, a gamete selection approach has not been applicable due to the lack of an efficient dihaploid generation system. Recently, two Lolium multiflorum Lam. lines were released (IL1, IL2) (Kindiger and Singh, 2011; Kindiger, 2012a) that allow low levels of dihaploid generation in hybrids when using the IL lines as the maternal parent in crosses that utilize tall fescue as the paternal parent (Kindiger, 2012b, 2016). Briefly, with the utilized approach, the generated F1 will occasionally loose either the IL (ryegrass) genome; or, the tall fescue genome through a mitotic genome loss behavior. This behavior gives rise to viable eggs cells having only a 
ryegrass or tall fescue genome. Both are receptive to fertilization. When such ovaries spontaneously double in chromosome number in the F1 inflorescence, a homozyougous, DH ryegrass (IL); or, a homozygous, tall fescue DH line are generated (Kindiger, 2012b, 2016). Gamete selection, as originally defined by Stadler (1944), is based on the principle that selection exerted at the gametophytic level can increase desirable allelic frequencies detectable at the sporophytic level. Sporophytic expressed traits are transmitted as genetic information through the gametes (sperm or egg nuclei) and contain half the information that is contained in the sporophytic tissue. If superior gametes can be recognized through appropriate selection methods, then such a system would theoretically be more efficient than one based on a zygotic selection strategy (Richey, 1947). Through the utilization of a paternal monoploid or dihaploid generation process, gamete selection has been a proven and efficient method of selection across numerous species (Stadler, 1944; Fehr, 1984; Snape et al., 1986; Schon et al., 1990; Lu et al., 1996; Rotarenco and Chalyk, 2000). In this methodology, the genetic contribution of the tall fescue gamete is the genotype of primary interest for tall fescue DH generation.

Dihaploid (DH) selection methods are well known for their ability to result in more rapid and efficient gains than other forms of selection (Singh, 1994; Hussain et al., 2012). In addition, the effectiveness of a DH selection approach is elevated when the number of genes governing a particular trait as quantitative in their inheritance (Kotch et al., 1992). The success of gamete selection is a more rapid breeding/selection approach and that no prior knowledge regarding the number of genes or inheritance of a trait is required (Singh, 1994). When applied to a polyploid species such as tall fescue, the gain in breeding efficiency could be exponential. Gamete selection, with early generation selection, has successfully been applied to the simultaneous selection of multiple traits, including quantitative trait loci governing characteristics such as seed yield, maturity, and tolerance to disease (Singh, 1994; Ravikumar and Patil, 2004). Though DH breeding methods, utilizing microspore tissue culture approaches, have been occasionally employed as a means to develop new Festulolium germplasm within the Festuca-Lolium complex of polyploid grasses (Humphreys et al., 2003; Guo and Yamada, 2004; Guo et al., 2005), the process is time consuming, tedious, genotypic specific and does not employ a gamete selection strategy.

Early research that utilized homozygous tall fescue derivatives, as generated through a standard selfing program, previously examined the inheritance of palatability (Henson and Buckner, 1957; Buckner and Fergus, 1960). Though the inbreeding process was time consuming, these studies indicated that the selection and development of homozygous lines can represent a useful methodology for the improvement of tall fescue. The success of this research also indicates that the application of a gamete selection approach aligned with the production of DH lines (Bouchez and Gallais, 2000) could result in a more efficient breeding approach for the production of tall fescue cultivars.

In the gamete selection approach presented here, a slight modification of a method presented by Stadler (1944) is utilized. In practice, gamete selection ordinarily involves two steps: 1) selection on the basis of outcross performance testing of individual plants of a variety or populations; and 2) a similar controlled selection for outstanding individuals exhibiting desirable agronomic attributes. Following the identification of superior genotypes, such individuals would undergo continued selfing, followed by phenotypic selection to generate homozygous stocks fixed for the desired agronomic characteristics. In instances where haploids can be generated through microspore culture, followed by genome doubling or some other method to induce homozygosity, homozygous or DH lines are the result. As with the Stadler gamete selection approach, the described approach reflects the situation where traits transmitted through the gamete are under the control of genes that are expressed in the sporophyte. But, unlike Stadler (op. cit.), a single gamete from the tall fescue parent fertilizes the egg of the inducer line (IL) which produces the F1 hybrid. Selection applied upon the F1 sporophyte and the tall fescue genome that it possesses constitutes the described form of gamete selection. Following the mitotic loss of one genome or the other, parthenogenesis occurs producing a viable embryo, but a seed lacking an endosperm (Kindiger, 2016). These events generally result in tall fescue $\mathrm{DH}$ recoveries possessing a normal genome constitution $(2 \mathrm{n}=6 \mathrm{x}=42)$ and occasional ryegrass $\mathrm{DH}$ recoveries possessing a normal, diploid genome constitution $(2 \mathrm{n}=2 \mathrm{x}=14)$. The described research examines the inheritance and expression of CP, ADF, NDF and IVDMD from the F1 stage to the DH recovery. The approach constitutes a gamete based DH technology that 
greatly enhances the production of homozygous DH lines and an understanding of the inheritance and expression of some forage quality attributes may identify a more efficient and effective approach for developing superior tall fescue DH lines and cultivars than traditional recurrent or mass-selection techniques.

\section{MATERIALS AND METHODS}

The USDA-ARS has recently released two annual ryegrass genetic stocks, identified as IL1 and IL2 (Kindiger and Singh, 2011; Kindiger, 2012a). Each is characterized by a genome loss phenomenon following hybridization with tall fescue, which is then followed by a low level of parthenogenic development of an embryo in the inflorescence. The IL1 and IL2 genetic stocks exhibit few advantageous agronomic characteristics and are notable primarily for their ability to induce genome loss following hybridization. That is, there are few if any advantageous agronomic traits such as persistence, disease tolerance, drought tolerance, etc. that could be seen as favorable agronomic traits. Each IL line is free of the fungal endophyte Epichloë sp. or Neotyphodium sp. (Carroll, 1988; Moon et al., 1994; Pedersen and Sleper, 1988).

Pollinations between the IL lines and tall fescue samples are described in detail elsewhere (Kindiger, 2012b, 2016) and only the general method is discussed here. IL $x$ tall fescue pollinations are generated by hand using the IL lines as the maternal parent and applying a bulk of randomly obtained tall fescue pollen from several commercial and public cultivars in the greenhouse. Bulk tall fescue pollen from one or multiple tall fescue pollen sources is utilized to take advantage of the diversity of available tall fescue gametes across genotypes. It should be noted that the ryegrass IL lines are self-incompatible which disallows selfing and the IL lines themselves segregate for pollen sterility. To achieve efficiency in producing IL $\mathrm{x}$ tall fescue F1 hybrids, these two traits, found in the IL lines are of high importance. Seed generated from the hybridizations is harvested and germinated in small trays containing a BM1 all purpose potting soil mixture (Berger, CA, USA) topsoil (local product). Eighty-five liters of the BM1 mix were blended with $18.14 \mathrm{~kg}$ of topsoil and blended by hand. Conditions for germination and plant growth were in a non-shaded, natural lighted greenhouse with a night to day temperature range from $21 \mathrm{C} 30 \mathrm{C}$. Trays and pots with germinating seedlings and plants were watered with overhead misters for approximately 2 hours daily. The resultant F1 hybrids were eventually transferred to eight inch pots filled with the potting mix-top soil blend described above. The F1 were allowed to grow to maturity in a pollen-free environment as prior investigations has indicated that though the F1 are generally female and seed sterile; it has been observed that some haploid eggs are viable and if pollen containment conditions are not utilized, uncontrolled pollination events would confound the generation and production of DH offspring (Kindiger, 2016). The F1 hybrids in the pollen isolated greenhouse were grown to maturity and, as is typical of such hybrids, were observed to be pollen sterile; however, it is noted that some level of pollen fertility can occasionally occur (Buckner, 1960; Buckner et al., 1961). If any F1 appeared to indicate some level of pollen fertility by exerting its anthers, it was removed to an adjoining greenhouse bay. When mature, the inflorescences were harvested and threshed by hand or machine to remove any stems. The cleaned seed heads were then placed in trays containing a light potting soil mix for germination and the eventual identification and selection for recovered ryegrass or tall fescue seedlings. It is important to note that embryo culture or embryo rescue methods were not employed for DH generation. Following two-to-three weeks of germination, seedlings were allowed to grow to an appropriate size to allow for phenotypic identification and eventual transplanting to pots. The germinating seedlings generally represent a mixture of ryegrass $\mathrm{DH}$ recoveries possessing a chromosome number of $2 \mathrm{n}=2 \mathrm{x}=14$ or tall fescue $\mathrm{DH}$ recoveries possessing a chromosome number of $2 n=6 x=42$. Discrimination between the ryegrass and tall fescue DH recoveries was performed by examination of phenotypic characters such as leaf width and growth habit and, as required, verified by chromosome counts. Counts were performed by methods published previously (Kindiger, 1996), then verified tall fescue DH seedlings was transferred to eight-inch pots containing a light potting soil mixture for further growth. DH tall fescue recoveries were also identified by molecular marker screenings (Kindiger, 2016).

In September 2011, 25 two-year-old F1's and one each of their respective one-year-old DH recoveries were transplanted to a non-replicated space-planted nursery at the of Kansas State University, Southeast Agricultural Research Center, Parsons, KS (Figure 1). The F1 and their respective DH offspring were transplanted adjacent to each other at a distance of $50 \mathrm{~cm}$, plant center-to plant center. These closely adjacent plantings were performed 
to minimize soil differences across the field that would affect the forage quality determinations. There was no intent in this experiment to evaluate forage quality across genotypes as the non-replicated nursery negated the ability to compare different genotypes in differing areas of the nursery due to anticipated field differences. Instead, the inheritance and expression of crude protein
(CP), Acid digestible fiber (ADF); neutral digestible fiber (NDF) and in vitro dry matter digestibility (IVDMD); each important forage quality components, were evaluated in the F1 and their respective DH offspring. The nursery was fertilized in October with $18 \mathrm{~kg} /$ ha granular nitrogen and weeding was performed by hand as necessary.

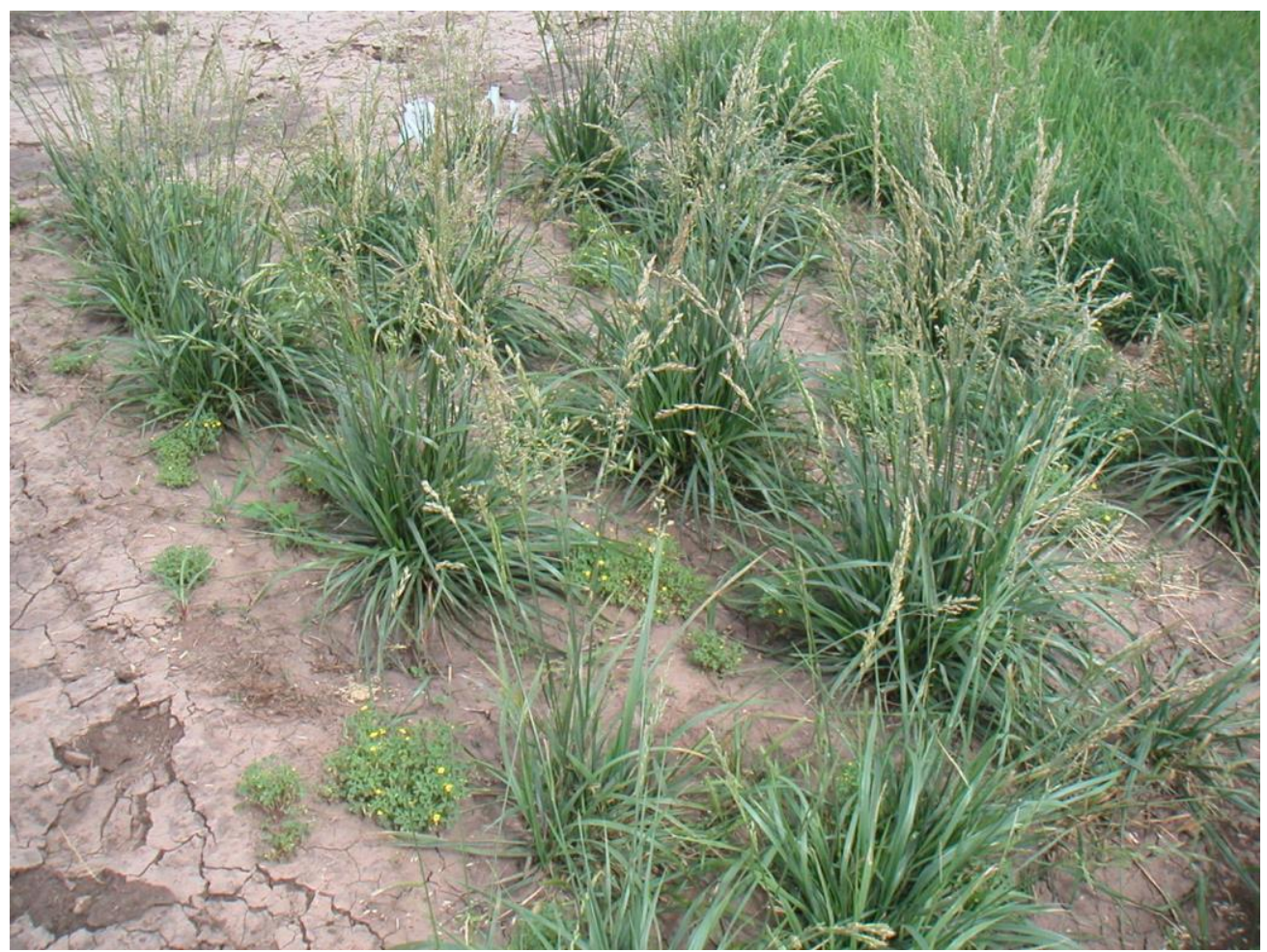

Figure 1. Spaced planting orientation of the nursery in Mound Valley, KS at the Kansas State University, Southeast Agricultural Research Center. The F1 and recovered DH were transplanted on 50cm centers in order to minimize known field variability.

On April 23, 2012, 25 wet leaf samples were obtained from the F1 and their twenty-five DH offspring. At least 300 grams of fresh leaf material per individual were obtained, sealed in Ziploc® bags and posted on a next day delivery schedule to ANALab, Fulton, IL for estimations of crude protein (CP), acid detergent fiber (ADF), neutral detergent fiber (NDF) and in vitro dry matter digestibility (IVDMD). ANALab dried the leaf materials and utilized NIR to obtain CP, ADF, NDF and IVDMD results (Table 1). A contingency chi-square test was applied using the combined F1's as the "observed" value and the combined $\mathrm{DH}$ values as the "expected" across all the samples to determine if the forage quality determinations of the combined F1 and DH offspring were, on average, statistically similar.

\section{RESULTS}

In this gamete selection approach, forage quality is conferred primarily by the genotype of the retained genome of the tall fescue individual that provided the single pollen grain (gamete) that generated the IL $x$ tall fescue hybrid. Forage quality components were evaluated at a single location, in an un-replicated, spaced planting nursery. Another approach to determine the expression of the forage quality traits could be performed with vegetative propagation of the $\mathrm{F} 1$ plants and the $\mathrm{DH}$ offspring, across several locations. This would allow an evaluation of forage quality expression across multiple selection pressures and how the genotypes are reacting to those differences. 
Table 1. Percent crude protein, ADF, NDF and IVDMD of F1 (LF) hybrids and their respective recovered DH lines.

Pair

Set Sample $\quad \mathrm{CP}^{1} \mathrm{ADF}^{2} \mathrm{NDF}^{3} \quad \mathrm{IVDMD}^{4}$

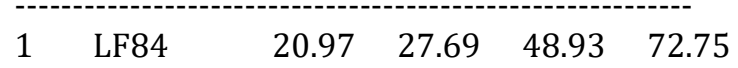

$\begin{array}{lllll}\text { DH117B } & 15.77 & 32.18 & 56.07 & 64.25\end{array}$

$2 \quad$ LF74 $\quad 19.74 \quad 29.9 \quad 53.52 \quad 68.04$

$\begin{array}{lllll}\text { DH105 } & 19.62 & 29.23 & 50.08 & 70.77\end{array}$

$\begin{array}{llllll}3 & \text { LF36 } & 23.27 & 27.09 & 47.75 & 72.37 \\ & \text { DH118B } & 25.18 & 32.39 & 55.16 & 65.14\end{array}$

$\begin{array}{llllll}- & \text { LF89 } & 19.32 & 26.67 & 56.65 & 73.10 \\ -------\end{array}$

$\begin{array}{lllll}\text { DH133B } & 19.84 & 29.47 & 55.83 & 67.56\end{array}$

$\begin{array}{llllll}- & \text { LF102 } & 19.73 & 27.57 & 49.65 & 72.55\end{array}$

$\begin{array}{lllll}\text { DH110B } & 19.53 & 31.17 & 54.89 & 75.91\end{array}$

$\begin{array}{llllll}6 & \text { LF90 } & 20.24 & 27.59 & 50.72 & 71.89 \\ & \text { DH120B } & 20.68 & 28.21 & 48.45 & 66.82\end{array}$

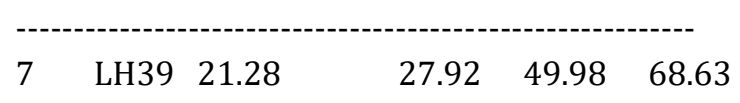

DH113B $\quad 19.89 \quad 30.76 \quad 52.84 \quad 66.52$

$\begin{array}{llllll}8 & \text { LF117 } & 17.45 & 31.25 & 56.59 & 67.18\end{array}$

$\begin{array}{lllll}\text { DH112B } & 19.06 & 31.18 & 52.98 & 66.56\end{array}$

$9 \quad$ LF99 $\quad 18.86 \quad 28.91 \quad 52.41 \quad 69.10$

$\begin{array}{lllll}\text { DH108 } & 20.68 & 29.51 & 50.29 & 69.74\end{array}$

$\begin{array}{llllll}10 & \text { LF65 } & 15.88 & 31.72 & 55.39 & 65.96 \\ & \text { DH119 } & 17.18 & 31.91 & 54.15 & 62.07\end{array}$

$11 \quad$ LF116 $\quad 17.41 \quad 30.48 \quad 54.86 \quad 65.04$

$\begin{array}{lllll}\text { DH115B } & 17.48 & 31.38 & 53.43 & 68.51\end{array}$

$\begin{array}{llllll}12 & \text { LF51 } & 17.33 & 31.63 & 55.28 & 64.92 \\ & \text { DH129B } & 15.64 & 29.21 & 48.09 & 67.96\end{array}$

$\begin{array}{llllll}13 & \text { LF94 } & 16.12 & 30.8 & 53.92 & 64.81 \\ & \text { DH124B } & 13.89 & 32.24 & 55.88 & 59.70\end{array}$

${ }^{1} \mathrm{CP}=$ percent crude protein

${ }^{2} \mathrm{ADF}=$ percent acid digestible fiber

${ }^{3} \mathrm{NDF}=$ percent neutral digestible fiber

${ }^{4}$ IVDMD - percent in vitro dry matter digestibility

\begin{tabular}{|c|c|c|c|c|c|}
\hline $\begin{array}{l}\text { Pair } \\
\text { Set }\end{array}$ & Sample & $C P^{1} A D$ & $F^{2} N D F^{3}$ & IVDMD & \\
\hline 14 & LF118 & 18.69 & 28.74 & 52.216 & 7.24 \\
\hline & DH126B & 17.11 & 26.63 & 47.44 & 66.71 \\
\hline 15 & LF107 & 16.71 & 30.92 & 53.37 & 64.55 \\
\hline & DH131B & 18.63 & 30.68 & 57.02 & 68.36 \\
\hline 16 & LF38 & 18.35 & 31.6 & 54.01 & 62.84 \\
\hline & DH132B & 17.09 & 32.13 & 54.34 & 63.27 \\
\hline 17 & LF100 & 14.74 & 30.59 & 53.49 & 61.98 \\
\hline & DH138B & 17.85 & 28.72 & 48.94 & 68.84 \\
\hline 18 & LF49 & 19.28 & 31.01 & 53.88 & 63.16 \\
\hline & DH130B & 19.75 & 29.81 & 52.12 & 64.47 \\
\hline 19 & LF72 & 19.31 & 29.79 & 52.62 & 66.88 \\
\hline & DH147B & 18.39 & 29.11 & 49.68 & 63.61 \\
\hline 20 & LF78 & 18.75 & 31.24 & 52.96 & 64.28 \\
\hline & DH144B & 17.42 & 32.23 & 58.03 & 67.09 \\
\hline 21 & LF93 & 18.27 & 29.79 & 52.99 & 69.85 \\
\hline & DH142B & 20.8 & 29.71 & 53.66 & 67.41 \\
\hline 22 & LF76 & 18.35 & 30.19 & 50.59 & 68.18 \\
\hline & DH154B & 18.45 & 29.46 & 51.04 & 65.79 \\
\hline 23 & LF109 & 16.92 & 32.54 & 56.44 & 64.40 \\
\hline & DH153B & 18.88 & 30.37 & 51.53 & 66.40 \\
\hline 24 & LF80 & 14.67 & 29.9 & 50.74 & 63.65 \\
\hline & DH152B & 16.29 & 28.64 & 49.01 & 66.11 \\
\hline 25 & LF111 & 15.83 & 31.54 & 55.81 & 61.49 \\
\hline & DH150B & 15.47 & 30.32 & 54.35 & 61.83 \\
\hline
\end{tabular}


Chi-square statistics were applied to the ANA Labs forage analysis results of $\mathrm{CP}, \mathrm{ADF}, \mathrm{NDF}$ and IVDMD. Chi-square values were $0.99(\mathrm{p}<0.05)$ for all traits, indicating no significant difference between the parental F1 and its respective DH offspring. This indicates that the inheritance and expression of the forage quality traits was primarily due to the tall fescue genome and was not compromised by the loss of the IL ryegrass genome. In other words, the retention of the tall fescue genome and all its forage quality traits, has full transfer to the dihaploid tall fescue genotype and expression of those traits is not hugely affected by the loss of any genes affecting any forage quality traits that are conferred by the presence/loss of the ryegrass genome. As an example, the estimated CP component of F1 hybrid LH74 was $19.74 \%$ while that of its DH recovery was $19.62 \%$. The values for ADF, NDF and IVDMD for the F1, LH74 were $29.9,53.52$ and $68.04 \%$, respectively, while those of its DH recovery were $29.35,53.74$ and $65.99 \%$, respectively. The loss of the ryegrass genome, with few if any favorable forage attributes, did not dramatically alter the forage quality of the recovered tall fescue $\mathrm{DH}$ when the ryegrass genome was lost. Most of the forage qualities were retained by the retention and doubling of the tall fescue genome in the dihaploid state. This represents the power of the 'gamete' selection approach and the ultimate development of dihaploid tall fescue that fixes the genotype of that tall fescue gamete in a homozygous, dihaploid state. The other F1 utilized in this study exhibited similar results (Table 1). These data suggest little difference between the forage quality characteristics of an F1 and its DH offspring. The lack of significant difference between the $\mathrm{F} 1$ and the respective DH line also indicates the IL line provided little forage quality attributes to the F1 parent. This outcome is advantageous as the exhibited forage attributes of each F1 and DH recovery can be attributed primarily by the genotype of the tall fescue gamete. It is also important to note that these data also suggest that selection for these forage qualities can be performed directly on the F1 and not delayed until the development of a DH recovery.

Presuming that $\mathrm{F} 1$ possessing higher $\mathrm{CP}$ are more desirable than those with lower $\mathrm{CP}$, that higher ADF is better than lower ADF, that lower NDF is superior to higher NDF, and that higher IVDMD values are superior to lower IVDMD values, then the F1 lines LF84, LF36, LF102 and LF89 of this study are the superior candidates for future $\mathrm{DH}$ recovery. It appears that evaluating quality traits against the F1 and identifying the superior F1 individuals in the first year of a study would greatly reduce the number of $\mathrm{F} 1$ necessary for $\mathrm{DH}$ generation and prioritize the research on F1 possessing superior genotypes. Once the F1 with the superior genotypes are identified, future efforts can be focused on obtaining DH lines from superior F1. This would also reduce the need for nursery space and for the extra year of effort that would have been focused on the maintenance of F1 and the development of DH lines exhibiting lesser quality attributes. Following this approach, the identified F1 would produce DH lines DH122B, DH118B; DH110B and DH133B that could be used for future research, hybridizations and breeding investigations.

These results suggest that a gamete selection approach, with the selection at the F1 level, will be highly effective and provide a good estimation of the CP, ADF, NDF and IVDMD qualities of any DH line that is derived from any particular F1 hybrid. As the DH recoveries retain most of the $\mathrm{CP}, \mathrm{ADH}, \mathrm{NDH}$ and IVDMD levels identified in their F1 parents, the most efficient utilization of this method would be to initiate selection of these traits on the F1 individuals rather than postponing selection at the $\mathrm{DH}$ recovery stage. By identifying F1 with elevated forage quality traits, the number and process of generating $\mathrm{DH}$ exhibiting lesser forage quality traits can be reduced or eliminated as only the F1 with the superior forage quality levels would be moved forward into a DH generation portion of the selection program.

\section{DISCUSSION}

Gamete selection greatly simplifies multi-gene or quantitative trait transfer within a breeding program when compared to traditional backcross, selfing or recurrent selection breeding methods (Maluszynski et al., 2003). As useful as DH breeding approaches can be (Brummer and Casler, 2009; Amini et al., 2011), these approaches are limited by the unavailability of such a methodology in many species; and as such, the generation of haploid or dihaploid lines through a gamete selection approach represents an unutilized approach for plant breeding and genetic analysis research (Dunwell, 2010). The proposed gamete selection breeding approach applied in this research offers a novel method for improving tall fescue germplasm. Differences in the forage values of CP, ADF, NDF and IVDMD across $25 \mathrm{~F} 1$ and 25 of their respective recovered $\mathrm{DH}$ lines is not significantly different. This suggests that selection for 
forage quality traits will be more efficient when performed at the F1 stage than at the subsequent DH generation stage. Since DH recoveries are a low frequency event, the effort expended on DH generation will be more efficient if F1 expressing superior forage quality traits were selected for future DH generation. F1 with a superior forage quality genotype will produce, homozygous DH lines possessing superior forage quality genotypes.

Though IL1 and IL2 can be utilized to generate DH lines, the frequency of generation is low, likely less than $1 \%$ (Kindiger and Singh, 2011), the ability to generate large numbers of $\mathrm{F} 1$ and the focus on the identification and selection of only superior F1 make this approach a highly beneficial breeding system. The generated IL x TF F1 hybrids can number in the thousands from a single IL $\mathrm{x}$ tall fescue hybridization. Due to the perennial nature of the F1, vegetative propagation can allow multi-location testing of identical genotypes, and numerous inflorescences can be available year after year. These advantages counter the low incidence of $\mathrm{DH}$ line recoveries from an $\mathrm{F} 1$. It should also be noted that the generation of a large number of $\mathrm{DH}$ from an $\mathrm{F} 1$ is unnecessary as most DH generated from a particular F1 will likely be identical in their genotype, barring mitotic inter-genomic recombination events. The successful generation of only one DH per F1 is all that is necessary to fix and propagate the genotype of a superior F1 hybrid. Gamete selection of forage quality traits in the F1 and the comparison of that same trait in the DH recoveries suggest this approach will be viable for the improvement of forage quality traits in tall fescue. In addition, the generation and availability of a DH line possessing a fixed genotype for that trait would prevent the loss or segregation of those genes if selfing within the DH line were utilized for seed increase. As with a hybrid maize production system, it may also be possible to combine these tall fescue DH lines for the production of tall fescue synthetics or true F1 hybrids that will capitalize on these and additional genotypic heterotic effects (Pinnell et al., 1952; Birchler et al., 2010). The replicated performance of this selection process over years and locations will provide additional forage quality information to the breeder.

The materials and procedures described herein apply directly to the breeding and selection of improved tall fescue genotypes. The sampling of hundreds of thousands of gametes via the pollen grains, each segregating for a myriad of genotypes from a single tall fescue individual or population along with selection on a sporophyte basis, represents a low input, low cost, rapid selection strategy that can be implemented across a diversity of environments. It is anticipated that, when applied correctly, this approach will not only be effective for the selection of forage quality attributes but will also be effective for the selection of both qualitative and quantitative traits. These might include maturity, drought tolerance, disease resistance, grazing persistence and forage yield. Such complex, quantitative traits could immediately be transferred to their $\mathrm{DH}$ recoveries.

The Festuca genus, the largest within the Loliinae subtribe of the Poaceae family, contains more than 500 species of temperate grasses (Inda et al., 2008). The genus varies substantially in ploidy levels, ranging from diploid $(2 \mathrm{n}=2 \mathrm{x}=14)$ to dodecaploid $(2 \mathrm{n}=12 \mathrm{x}=84)$, with the vast majority of species being allopolyploid. It is anticipated that gamete selection within the F1 generated by many of these species will also be highly effective. Studies are now underway to evaluate this hypothesis. The following patents have been assigned and awarded to the USDA-ARS for the technology presented in this publication: US Patent No. 20,100,083,400; 9.958,107; New Zealand Patent No. 592035; Australian Patent No. 2015246971; Canadian Patent No. 2,738,762. Recent investigations utilizing the inducer dihaploid selection approach in meadow fescue and festulolium have been promising and suggest this approach will be equally effective for selection and improvement of forage quality attributes in these species. U.S patent application SN $16 / 575,792$ has been submitted to the USPVPO and foreign patent submissions are pending.

\section{REFERENCES}

Amini, F., A. Mirlohi, M. M. Majidi, S. ShojaieFar and R. Kölliker. 2011. Improved polycross breeding of tall fescue through marker-based parental selection. Plant Breeding, 130: 701-07. https://doi.org/10.1111/i.1439$\underline{0523.2011 .01884 . \mathrm{X}}$

Birchler, J. A., H. Yao, S. Chudalayandi, D. Vaiman and R. A. Veitia. 2010. Heterosis. The Plant Cell, 22: 2105-12. https://doi.org/10.1105/tpc.110.076133

Bouchez, A. and A. Gallais. 2000. Efficiency of the Use of Doubled-Haploids in Recurrent Selection for Combining Ability. Crop Science, 40: 23. https://doi.org/10.2135/cropsci2000.40123x

Brummer, C., E. and M. D. Casler. 2009. Improving Selection in Forage, Turf, and Biomass Crops Using 
Molecular Markers. In: $\mathrm{T}$ Yamada and $\mathrm{G}$ Spangenberg (eds.), Molecular Breeding of Forage and Turf, The proceedings of the 5th International Symposium on the Molecular Breeding of Forage and Turf Springer New York.

https://doi.org/10.1007/978-0-387-79144-9 18

Buckner, R. C. 1960. Cross-Compatibility of Annual and Perennial Ryegrasses with Tall Fescue. Agronomy Journal, 52: 409.

https://doi.org/10.2134/agronj1960.000219620 $\underline{05200070016 \mathrm{x}}$

Buckner, R. C. and E. N. Fergus. 1960. Improvement of Tall Fescue for Palatability by Selection Within Inbred Lines. Agronomy Journal, 52: 173.

https://doi.org/10.2134/agronj1960.000219620 $\underline{05200030016 \mathrm{x}}$

Buckner, R. C., H. D. Hill and P. B. Burrus. 1961. Some Characteristics of Perennial and Annual Ryegrass $\times$ Tall Fescue Hybrids and of the Amphidiploid Progenies of Annual Ryegrass $\times$ Tall Fescue. Crop Science, 1: 75.

https://doi.org/10.2135/cropsci1961.0011183x0 $\underline{00100010022 \mathrm{x}}$

Carroll, G. 1988. Fungal Endophytes in Stems and Leaves: From Latent Pathogen to Mutualistic Symbiont. Ecology, 69: 2-9. https://doi.org/10.2307/1943154

Dunwell, J. M. 2010. Haploids in flowering plants: origins and exploitation. Plant Biotechnology Journal, 8: 377-424.

https://doi.org/10.1111/j.14677652.2009.00498.x

Fehr, W. 1984. Homozygous Lines from Double Haploids. In, Principles of Cultivar Development Vol. 1 Macmillan Publishing Company: New York.

Guo, Y., Y. Mizukami and T. Yamada. 2005. Genetic Characterization of Androgenic Progeny Derived from Lolium Perenne $\times$ Festuca Pratensis Cultivars. New Phytologist, 166: 455-64.

https://doi.org/10.1111/j.14698137.2005.01345.X

Guo, Y. and T. Yamada. 2004. High Frequency Androgenic Embryogenesis and Genome Size Variation in Pollen-Derived Festulolium. In: T Yamada and $\mathrm{T}$ Takamizo (eds.), Development of a Novel Grass with Environmental Stress Tolerance and High Forage Quality Through Intergeneric Hybridization between Lolium and Festuca The National Agriculture and Food Research Organization:
Ibaraki, Japan.

Hand, M. L., N. O. Cogan, A. V. Stewart and J. Forster. 2010. Evolutionary History of Tall Fescue Morphotypes Inferred from Molecular Phylogenetics of the Lolium-Festuca Species Complex. BMC evolutionary biology, 10: 303. https://doi.org/10.1186/1471-2148-10-303

Henson, L. and R. Buckner. 1957. Resistance to Helminthosporium dictyoides in Inbred Lines of Festuca arundinacea. Phytopathology, 47: 523-23.

Humphreys, M., H.-M. Thomas, J. Harper, G. Morgan, A. James, A. Ghamari-Zare and H. Thomas. 1997. Dissecting Drought and Cold Tolerance Traits in the Lolium-Festuca Complex by Introgression Mapping. New Phytologist, 137: 55-60. https://doi.org/10.1046/i.14698137.1997.00832.x

Humphreys, M. W., P. J. Canter and H. M. Thomas. 2003. Advances in Introgression Technologies for Precision Breeding within the Lolium - Festuca Complex. Annals of Applied Biology, 143: 1-10. https://doi.org/10.1111/i.17447348.2003.tb00263.x

Hussain, B., M. A. Khan, Q. Ali and S. Shaukat. 2012. Double Haploid Production is the Best Method for Genetic Improvement and Genetic Studies of Wheat. International Journal for Agro Veterinary and Medical Sciences, 6: 216-28.

Inda, L. A., J. G. Segarra-Moragues, J. Müller, P. M. Peterson and P. Catalán. 2008. Dated historical biogeography of the temperate Loliinae (Poaceae, Pooideae) grasses in the northern and southern hemispheres. Molecular Phylogenetics and Evolution, 46: 932-57. https://doi.org/10.1016/i.ympev.2007.11.022

Jennings, J. A., P. Beck and C. P. West. 2008. Tall Fescue for Forage. In University of Arkansas Extension Bulletin (Ed.),Department of Agricultural and Natural Resources. Fayetteville, AR., USA.

Kasperbauer, M. J. 1990. Biotechnology in Tall Fescue ImprovementCRC Press. Boca Raton, FL., USA.

Kindiger, B. 1996. A Technique for the Preparation of Somatic Chromosomes of Maize. In: M Freeling and V Walbot (eds.), The Maize Handbook Springer New York. https://doi.org/10.1007/978-1-4612-2694-9 74

Kindiger, B. 2012a. Notification of the Release of Annual Ryegrass Genetic Stock IL1. Journal of Plant Registrations, 6: 117-20. 
Kindiger, B. 2012b. Sampling the Genetic Diversity of Tall Fescue Utilizing Gamete Selection. In: M Caliskan (ed.), Genetic Diversity in Plants InTech. https://doi.org/10.5772/33273

Kindiger, B. 2016. Generation of Paternal Dihaploids in Tall Fescue. Grassland Science, 62: 243-47. https://doi.org/10.1111/grs.12133

Kindiger, B. and D. Singh. 2011. Registration of Annual Ryegrass Genetic Stock IL2. Journal of Plant Registrations, 5: 254-56. https://doi.org/10.3198/jpr2010.08.0458crgs

Kotch, G. P., R. Ortiz and S. J. Peloquin. 1992. Genetic Analysis by Use of Potato Haploid Populations. Genome, 35: 103-08. https://doi.org/10.1139/g92-018

Lu, C., L. Shen, Z. Tan, Y. Xu, P. He, Y. Chen and L. Zhu. 1996. Comparative Mapping of QTLs for Agronomic Traits of Rice Across Environments using a Doubled Haploid Population. Theoretical and Applied Genetics, 93: 1211-17. https://doi.org/10.1007/s001220050358

Maluszynski, M., K. J. Kasha, P. B. Forster and I. Szarejko. 2003. Doubled Haploid Production in Crop PlantsA Manual. Kluwer Academic Publications. Dordrecht, Boston, London.

Moon, C. D., B. A. Tapper and B. Scott. 1994. Identification of Epichloë Endophytes In Planta by a Microsatellite-Based PCR Fingerprinting Assay with Automated Analysis. Applied and Environmental Microbiology, 65: 1268-79. https://doi.org/10.1128/aem.65.3.1268$\underline{1279.1999}$

Pedersen, J. F. and D. A. Sleper. 1988. Considerations in Breeding Endophyte-Free Tall Fescue Forage Cultivars. Journal of Production Agriculture, 1: 127-32.

https://doi.org/10.2134/jpa1988.0127
Pinnell, E. L., E. H. Rinke and H. K. Hayes. 1952. Gamete Selection for Specific Combining Ability. In: J. W. Gowan (ed.), Heterosis Iowa State College Press: Ames, IA.

Ravikumar, R. L. and B. S. Patil. 2004. Effect of Gamete Selection on Segregation of Wilt SusceptibilityLinked DNA Marker in Chickpea. Current Science, 86: 642-43.

Richey, F. D. 1947. Corn Breeding: Gamete Selection, the Oenothera Method, and Related Miscellany. Agronomy Journal, 39: 403. https://doi.org/10.2134/agronj1947.000219620 $\underline{03900050007 x}$

Rotarenco, V. A. and S. T. Chalyk. 2000. Selection at the Level of Haploid Sporophyte and its Influence on the Traits of Diploid Plants in Maize. Genetika, 32: 479-85.

Schon, C., M. T. Sanchez, M. Blake and P. M. Hayes. 1990. Segregation of Mendelian Markers in Doubled Haploid and F2 Progeny of Barley Cross. Hereditas, 113: 69-72.

Singh, S. P. 1994. Gamete Selection for Simultaneous Improvement of Multiple Traits in Common Bean. Crop Science, 34: 352-55.

Snape, J. W., E. Simpson, B. B. Parker, W. Friedt and B. Foroughi-Wehr. 1986. Criteria for the Selection and Use of Doubled Haploid Systems in Cereal Breeding programmes. In: W Horn, C. J Jensen, W Odenbach and $O$ Schieder (eds.), Genetic Manipulation in Plant Breeding De Gruyter. https://doi.org/10.1515/9783110871944-038

Stadler, L. J. 1944. Gamete Selection in Corn Breeding. American Society of Agronomy, 36: 988-89.

Volaire, F. and M. Norton. 2006. Summer Dormancy in Perennial Temperate Grasses. Annals of Botany, 98: 927-33.

https://doi.org/10.1093/aob/mcl195

Publisher's note: ESci Journals Publishing remains neutral with regard to jurisdictional claims in published maps and institutional affiliations.

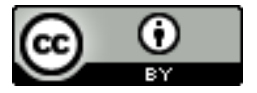

Open Access This article is licensed under a Creative Commons Attribution 4.0 International License, which permits use, sharing, adaptation, distribution and reproduction in any medium or format, as long as you give appropriate credit to the original author(s) and the source, provide a link to the Creative Commons license and indicate if changes were made. The images or other third-party material in this article are included in the article's Creative Commons license, unless indicated otherwise in a credit line to the material. If material is not included in the article's Creative Commons license and your intended use is not permitted by statutory regulation or exceeds the permitted use, you will need to obtain permission directly from the copyright holder. To view a copy of this license, visit http://creativecommons.org/licenses/by/4.0/.

(C) The Author(s) 2019. 